\title{
Histaminergic $\mathrm{H}_{3}$-Heteroreceptors as a Potential Mediator of Betahistine- Induced Increase in Cochlear Blood Flow
}

\author{
Mattis Bertlich ${ }^{a}$ Friedrich Ihler $^{a}$ Saskia Freytag ${ }^{b}$ Bernhard G. Weiss ${ }^{a}$ \\ Michael Strupp ${ }^{c}$ Martin Canis ${ }^{a}$ \\ ${ }^{a}$ Department of Otorhinolaryngology, Head and Neck Surgery, University of Göttingen Hospital, and bepartment \\ of Genetic Epidemiology and Biostatistics, University of Göttingen Medical School, Göttingen, and 'Department \\ of Neurology and German Center for Vertigo and Balance Disorders, University Hospital Munich - Campus \\ Grosshadern, Munich, Germany
}

\section{Key Words}

Betahistine $\cdot \mathrm{H}_{3}$-receptors $\cdot \mathrm{H}_{1}$-receptors $\cdot \mathrm{a}_{2}$-receptors .

Ménière's disease $\cdot$ Cochlea $\cdot$ Microcirculation .

Fluorescence microscopy

\begin{abstract}
Objective: Betahistine is a histamine-like drug that is considered beneficial in Ménière's disease by increasing cochlear blood flow. Acting as an agonist at the histamine $\mathrm{H}_{1}$-receptor and as an inverse agonist at the $\mathrm{H}_{3}$-receptor, these receptors as well as the adrenergic $a_{2}$-receptor were investigated for betahistine effects on cochlear blood flow. Materials and Methods: A total of 54 Dunkin-Hartley guinea pigs were randomly assigned to one of nine groups treated with a selection of $\mathrm{H}_{1}-, \mathrm{H}_{3}$ - or $\mathrm{a}_{2}$-selective agonists and antagonists together with betahistine. Cochlear blood flow and mean arterial pressure were recorded for $3 \mathrm{~min}$ before and $15 \mathrm{~min}$ after infusion. Results: Blockage of the $\mathrm{H}_{3}$ - or $\mathrm{a}_{2}$-receptors caused a suppression of betahistine-mediated typical changes in cochlear blood flow or blood pressure. Activation of $\mathrm{H}_{3}$-receptors caused a drop in cochlear blood flow and blood pressure. $\mathrm{H}_{1}$-receptors showed no involvement in betahistinemediated changes of cochlear blood flow. Conclusion: Betahistine most likely affects cochlear blood flow through histaminergic $\mathrm{H}_{3}$-heteroreceptors.

(c) 2015 S. Karger AG, Basel
\end{abstract}

(c) 2015 S. Karger AG, Base

$1420-3030 / 15 / 0205-0283 \$ 39.50 / 0$

\section{Introduction}

In 1861, Prosper Ménière was the first to ascribe a certain combination of tinnitus, one-sided hearing loss and an extreme feeling of vertigo not to the brain but to the inner ear [Ménière, 1861a, b]. Not much later, this triad of symptoms was being referred to as 'maladie de Ménière', Ménière's disease [Thorp and James, 2005].

The most common approach in Europe for the treatment of Ménière's disease is the continuous oral application of betahistine dihydrochloride. Betahistine has been used in the treatment of Ménière's disease for decades; hence clinical trials and meta-analyses of its efficacy are numerous. It is commonly accepted that repetitive daily doses of betahistine are capable of reducing the number and gravity of attacks during the course of the disease [Claes and Van de Heyning, 1997, 2000; James and Burton, 2001; James and Thorp, 2005].

However, to this day it is not clear how betahistine acts in Ménière's disease. It has been proposed that betahistine, through its histamine-like properties, might increase vascular permeability and thus decrease the endolymphatic hydrops that is the cause of Ménière's disease [Ber-

Some of this work is part of the doctoral thesis of Mattis Bertlich.

\section{KARGER 125}

E-Mail karger@karger.com

www.karger.com/aud
Prof. Martin Canis, MD

Department of Otorhinolaryngology, Head and Neck Surgery

University of Göttingen Hospital

Robert-Koch-Strasse 40, DE-37075 Göttingen (Germany)

E-Mail martin.canis@med.uni-goettingen.de 
lin et al., 2011]. Moreover, betahistine could aid in the central-nervous compensation that takes place after a patient has suffered from an attack [Redon et al., 2011]. Lastly, it has been shown that betahistine is capable of increasing cochlear blood flow in animal models and could therefore aid in the reduction of the endolymphatic hydrops [Dziadziola et al., 1999; Laurikainen et al., 2000; Ihler et al., 2012a]. So far, this has been viewed as the most likely mechanism of action in Ménière's disease [Strupp et al., 2011].

Betahistine is a structural analog of histamine that has been shown to act as a potent inverse agonist on histamine $\mathrm{H}_{3}$-receptors [Gbahou et al., 2010] and as a weaker agonist on $\mathrm{H}_{1}$-receptors [Fossati et al., 2001]. It is commonly accepted that betahistine has no effect whatsoever on histaminergic $\mathrm{H}_{2}$-receptors [Curwain et al., 1972; Laurikainen et al., 1998; Fossati et al., 2001]. Moreover, there have been results that suggest that betahistine also affects another class of receptors, potentially of the adrenergic a-receptor subfamily [Dziadziola et al., 1999]. To this day, the receptors by which betahistine increases cochlear microcirculation have not been investigated systematically and have only been assessed in a scattered manner. A potential cause for this is the early approval of betahistine in the late 60 s of the previous century, when a considerably lower pharmacological understanding of a drug was required for approval. Moreover, the exact mode of action of betahistine at the histaminergic $\mathrm{H}_{3}$-receptor was only been discovered in 2010 [Gbahou et al., 2010]. To this day, the receptors investigated as mediators of betahistine effects have included histaminergic [Laurikainen et al., 1998; Dziadziola et al., 1999], cholinergic [Laurikainen et al., 1993], adrenergic [Laurikainen et al., 1998] and imidazole receptors [Laurikainen et al., 1998].

The aim of this study was to systematically evaluate the receptor or receptors that give rise to the increase in cochlear blood flow caused by betahistine.

\section{Materials and Methods}

\section{Animals}

A total of 54 healthy female Dunkin-Hartley guinea pigs (180$300 \mathrm{~g}$ ) obtained from Charles River Laboratories (Sulzfeld, Germany) were included in the study. All experiments were performed according to German state regulations for animal experimentation and were approved by the responsible authorities, the Niedersächsische Landesamt für Verbraucherschutz und Lebensmittelsicherheit (LAVES, Oldenburg, Germany; animal license No. 33.11.42502-04-012/889).

The animals initially received buprenorphine $0.05 \mathrm{mg} / \mathrm{kg}$ body weight subcutaneously. Approximately $30 \mathrm{~min}$ after the initial ap- plication of buprenorphine, the animals were sedated using a mixture of ketamine $(8.5 \mathrm{mg} / \mathrm{kg}$ body weight $)$ and midazolam $(0.75 \mathrm{mg} /$ $\mathrm{kg}$ body weight). After the animals were fully sedated, anesthesia was continued throughout the experiments by the continuous inhalation of $3 \%$ isoflurane.

The preparative surgery in the experiments lasted on average about $90 \mathrm{~min}$ and the measurements $18 \mathrm{~min}$. Following the experiments, the animals were euthanized.

\section{Surgical Preparation and Intravital Imaging}

Surgical preparation and intravital microscopy for measuring microcirculation parameters were performed as described elsewhere [Canis et al., 2010; Ihler et al., 2012b]. Utilizing microsurgery, a polyethylene catheter was placed in the left jugular vein for the application of fluids, agents and contrast material. A pressure transducer was placed in the right femoral artery. Finally, the right ear was removed and the underlying bulla carefully opened. A rectangular window of approximately $0.2 \times 0.2 \mathrm{~mm}$ was carved into the exposed cochlea.

As previously described, intravital microscopy allowed direct examination and recording of stria vascularis vessels [Nuttall, 1987]. Utilizing FITC (fluorescein isothiocyanate)-labeled dextran (molecular weight 500,$000 ; 0.2-0.4 \mathrm{ml}$ of a $5 \%$ solution in $0.9 \%$ $\mathrm{NaCl}$; Sigma, Deisenhofen, Germany) that had been injected intravenously as a plasma marker, it was possible to differentiate the intravasal erythrocytes from the FITC-dyed plasma. The images were obtained using illumination with a Leica EL6000 light source (Leica Microsystems, Wetzlar, Germany) linked to a Leica M205 FA stereomicroscope. The data generated was processed with the proprietary Leica Application Suite software and then saved on a digital hard drive for later off-line analysis. Velocity (micrometers per second) and diameter (micrometers) of stria vascularis vessels were measured after the surgical procedure with the image analyzation system Cap-Image (Dr. Zeintl Biomedical Engineering, Heidelberg, Germany) [Zeintl et al., 1989; Klyscz et al., 1997]. During analysis of the acquired data, three representative vessels for each animal were selected. For these vessels, three values for intravascular blood flow and three values for the respective diameter were obtained each minute. These values were then averaged for each minute and, utilizing the formula postulated by Baker and Wayland, they were used to calculate the intravascular blood flow for each minute. The formula was given as $\mathrm{q}=(\mathrm{v} / 1.6) \times(\mathrm{d} / 2)^{2} \times \pi$, where $q$ represents the intravascular blood flow, $v$ the intravascular velocity and $d$ the vessel diameter [Baker and Wayland, 1974]. In order to correct for interindividual differences, cochlear blood flow was reported in arbitrary units (AU), thus reflecting the relative change from the initially obtained basal values.

The originally obtained basal values for intravascular blood flow ranged from 2 to $56 \mu \mathrm{l} / \mathrm{s}$, depending on the animal and vessel examined. Potential reasons for this wide range of data sets include a possible impairment or injury of the vessels during the surgical preparation or drying out of the capillaries during fluorescence microscopy. Moreover, the fewer times a capillary had branched up before the point in which the measurements were taken, the greater the diameter and the larger the intravasal blood flow. To calculate relative change in cochlear blood flow, an average of the three basal values of each vessel was calculated. Any value recorded in this vessel was then divided by this average basal value. Finally, an average value for each minute was calculated from the relative change values for each vessel. 
Measurement of Mean Arterial Pressure

Mean arterial pressure was recorded using a Fiber-Optic Pressure Measurement System by Samba Sensors AB (Västra Frölunda, Sweden) [Woldbaek et al., 2003]. The fiber-optic catheter was inserted into the right femoral artery. For the duration of the experiments, the results were automatically recorded with a Samba 201 Control Unit, with a rate of 40 measurements per second. The ensuite Samba 200 control software was used for later analysis of the acquired data. The basal data sets for mean arterial pressure ranged from 14 to $79 \mathrm{~mm} \mathrm{Hg}$. Potential reasons for this data set include early circulatory failure caused by prolonged surgical preparation and interindividually different reactions to the anesthesia caused by variations in age or weight of the animals.

To correct for differences between individual animals, changes in blood pressure are reported as $\mathrm{AU}$, reflecting the relative change. AUs were calculated by dividing each value obtained for mean arterial pressure by an average of the three basal values obtained for each individual.

\section{Calculation of Normalized Cochlear Blood Flow}

Normalized cochlear blood flow [Baldwin et al., 1992; Ohlsen et al., 1992] was calculated by dividing the obtained arbitrary values for cochlear blood flow by the arbitrary values obtained for the mean arterial pressure, allowing us to report a relative change in cochlear blood flow without units, corrected for potential systemic influences.

\section{Treatment Protocol}

The 54 animals were randomly assigned to one of nine groups (betahistine plus placebo, betahistine plus demethylbetahistine, betahistine plus diphenhydramine, betahistine plus a-methylhistamine, betahistine plus thioperamide, betahistine plus proxyfan, betahistine plus idazoxan, betahistine plus yohimbine, ciproxifan without betahistine) and underwent microsurgery as reported above. As soon as a clear picture could be taken, baseline measurements were recorded for $3 \mathrm{~min}$. After the baseline measurements had been acquired, a 2-min infusion of the appropriate treatment was begun. Upon the beginning of the infusion, both cochlear blood flow and mean arterial pressure were recorded for 15 more minutes.

\section{Statistical Analysis}

Statistical analysis was carried out by Project R for Mac 3.0.0 GUI 1.60 Snow Leopard build (The R Foundation for Statistical Computing; http://www.r-project.org). Two-way analysis of variance (ANOVA) was used to detect significant differences; measurements of the treatment groups were compared with placebo at each given time point. In order to correct for multiple testing for different groups and time points, a Bonferroni t test was performed. A p value of $\alpha<0.05$ was considered to be statistically significant.

\section{Results}

The Effect of Histaminergic $H_{1}$-Receptors on Cochlear Blood Flow and Normalized Cochlear Blood Flow

Infusion of betahistine together with demethylbetahistine, a histaminergic $\mathrm{H}_{1}$-receptor agonist, caused a general drop in cochlear blood flow. From min 5 onwards, in which cochlear blood flow showed a brief increase, blood flow remained at a plateau around baseline level up to minute 11 (mean value for minutes $4-11=1.008 \mathrm{AU}$, standard deviation, $\mathrm{SD}=0.116$ ); from then on there was a strong tendency for blood flow to decrease. The average for the group receiving betahistine together with placebo in the same period of time was $1.180 \mathrm{AU}(\mathrm{SD}=0.235)$. The lowest value was $0.766 \mathrm{AU}$ at minute 18 .

The group receiving betahistine together with the $\mathrm{H}_{1}$ antagonist diphenhydramine showed no significant differences to the group that was treated with betahistine together with placebo.

None of the groups treated with betahistine plus diphenhydramine or betahistine showed a significant impact on normalized cochlear blood flow in comparison with the control group that was treated with betahistine together with a placebo (fig. 1,2).

\section{The Effect of Histaminergic $\mathrm{H}_{3}$-Receptors on Cochlear}

\section{Blood Flow and Normalized Cochlear Blood Flow}

Infusion of the histamine $\mathrm{H}_{3}$-receptor agonist a-methylhistamine showed significant differences in comparison with control from minutes 6 to 18 . There was a general tendency of the cochlear blood flow to decrease under infusion of $\alpha$-methylhistamine; the average value for minutes $6-18$ was at $0.805 \mathrm{AU}(\mathrm{SD}=0.225)$. The average for the placebo group in the same period of time was 1.219 AU ( $\mathrm{SD}=0.176)$.

The group receiving the histamine $\mathrm{H}_{3}$-receptor antagonist thioperamide together with betahistine showed no major elevation from baseline; the changes in cochlear blood flow typical for betahistine were reversed. The mean value for minutes $4-18$ was $0.994 \mathrm{AU}(\mathrm{SD}=0.101)$. The values from minutes 7 to 18 are significantly different from the group receiving betahistine with placebo.

The same can be said about the group receiving the $\mathrm{H}_{3}$-protean agonist proxyfan simultaneously with betahistine. Cochlear blood flow did not differ greatly from baseline throughout the entire observation. Minutes 8-18 differed significantly from the placebo group.

In the group that had received ciproxifan without betahistine, a $\mathrm{H}_{3}$-selective inverse agonist/antagonist showed slightly increased cochlear blood flow. The average value for minutes $4-18$ was $1.091 \mathrm{AU}(\mathrm{SD}=0.063$ ). Minutes 9-12 were significantly different from the betahistine group receiving solely betahistine.

No significant changes in normalized cochlear blood flow were observed in any group treated with betahistine together with histaminergic $\mathrm{H}_{3}$-receptor agonists or antagonists in comparison with the control group (fig. 1,2). 

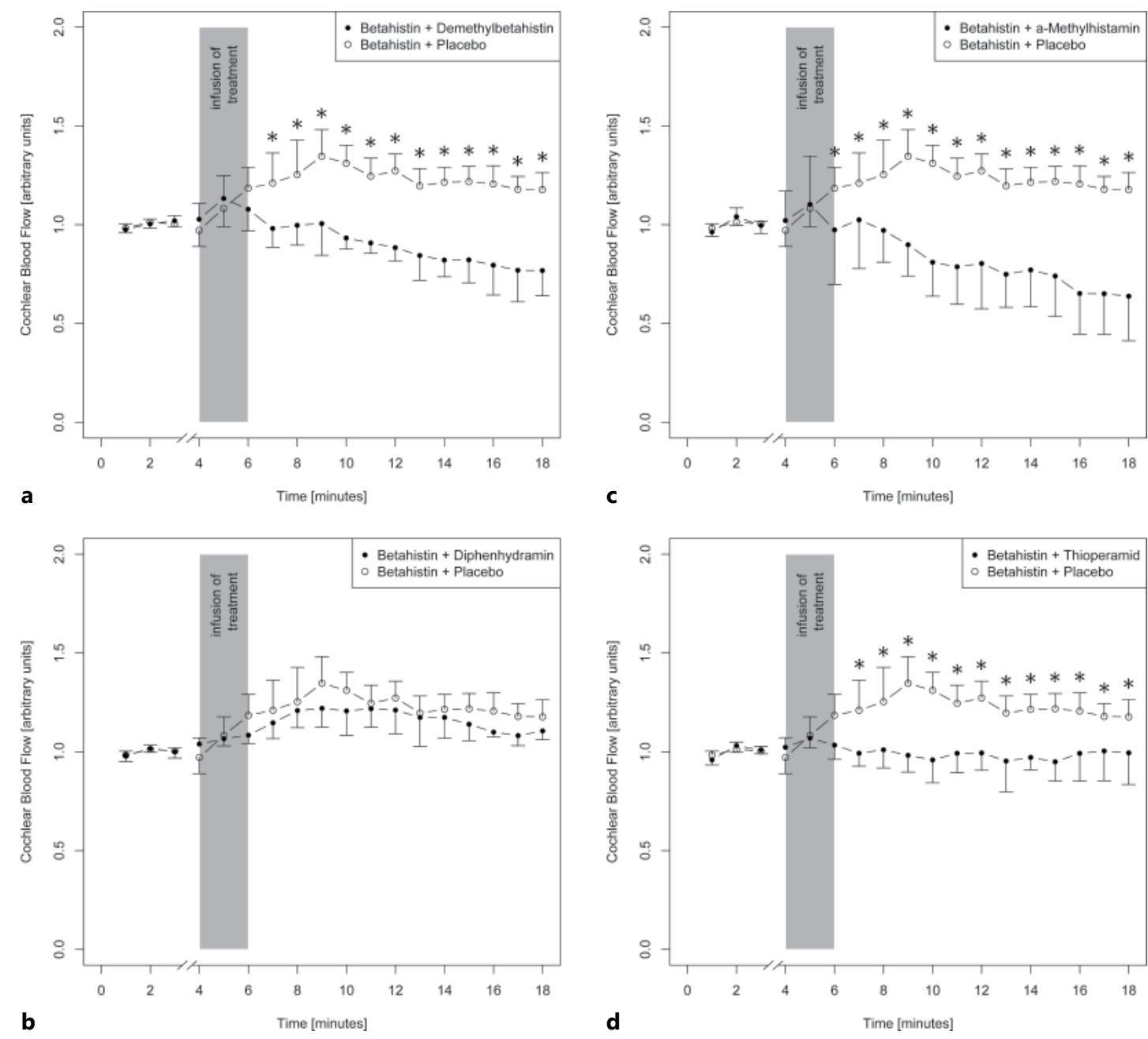

Fig. 1. Cochlear blood flow over time before and after infusion of betahistine together with treatment. a Betahistine plus demethylbetahistine. b Betahistine plus diphenhydramine. c Betahistine plus $\alpha$-methylhistamine. d Betahistine plus thioperamide. e Beta-

histine plus proxyfan. $\mathbf{f}$ Ciproxifan. $\mathbf{g}$ Betahistine plus idazoxan. $\mathbf{h}$ Betahistine plus yohimbine. Data are presented as means \pm SD. $* \mathrm{p}<0.05$.

(For figure 1e-h see next page.)

The Effect of Adrenergic $\alpha_{2}$-Receptors on Cochlear Blood Flow and Normalized Cochlear Blood Flow

The group receiving idazoxan showed a slight initial drop in cochlear blood flow. The lowest value at minute 4 was $0.889 \mathrm{AU}(\mathrm{SD}=0.059)$. After a recovery up to minute 3 , cochlear blood flow remained steady around baseline level. The average for minutes $7-18$ was $1.011 \mathrm{AU}$ $(\mathrm{SD}=0.046)$. Minutes $5-17$ were significantly different from the placebo group.

Infusion of betahistine together with yohimbine showed no change from basal values upon infusion or in the period thereafter. Cochlear blood flow in minutes
7-16 was significantly different from cochlear blood flow in the group receiving betahistine together with placebo.

None of the groups treated with betahistine and adrenergic $\alpha_{2}$-receptor antagonists displayed significant changes in normalized cochlear blood flow in comparison with the group receiving betahistine with placebo (fig. 1, 2).

\section{The Effect of $H_{1}$-Receptors on Mean Arterial Pressure}

The group that was treated with demethylbetahistine showed an initial, yet steep, rise with a peak at minute 5 of 1.374 AU ( $\mathrm{SD}=0.496)$. From then on, blood pressure showed a general tendency to decrease. Significant differ- 

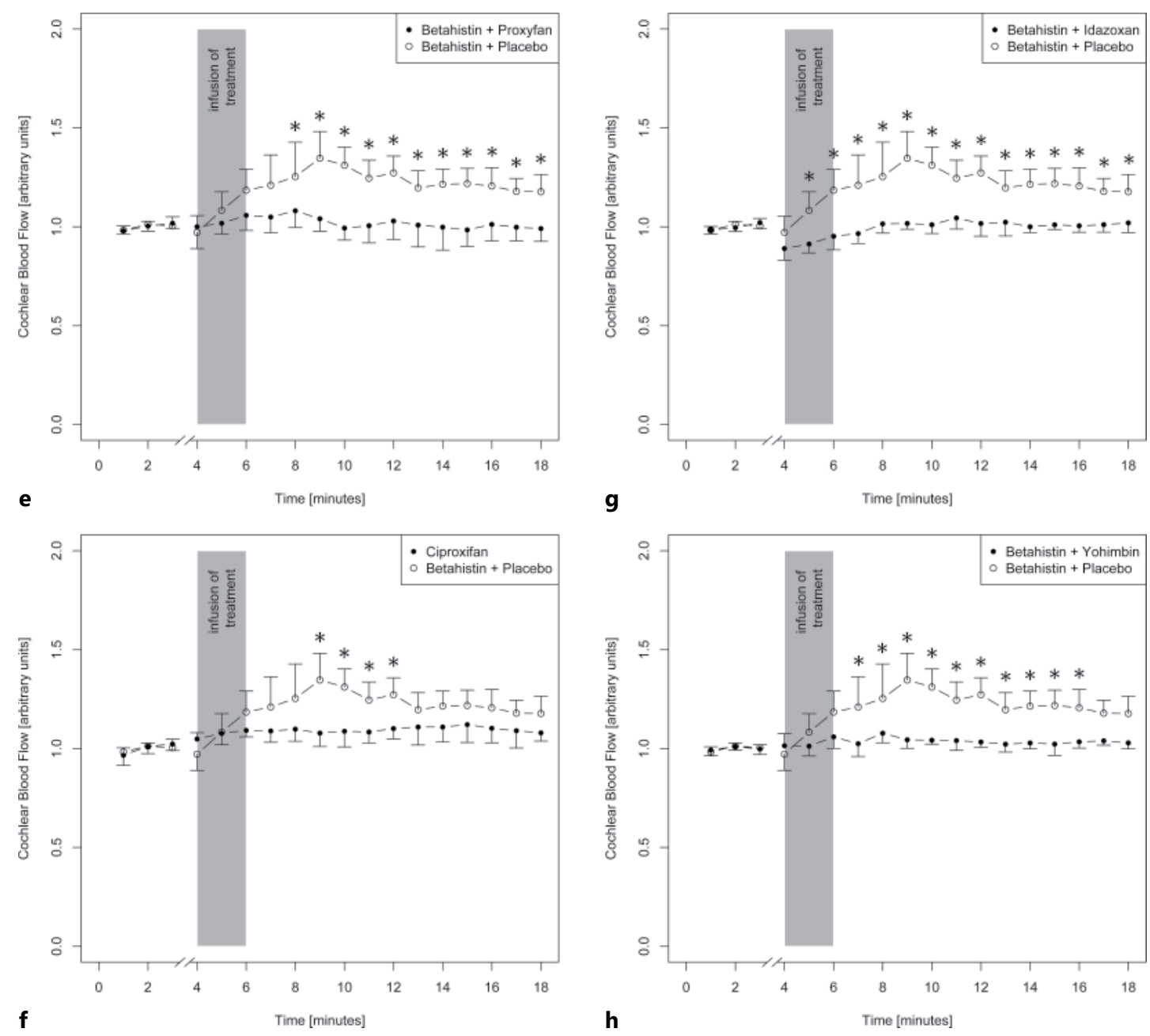

ences from placebo were detected at minutes 5 and 9-18. The group receiving diphenhydramine showed no significant differences from the control group (fig. 3).

The Effect of $\mathrm{H}_{3}$-Receptors on Mean Arterial Pressure Infusion of $\alpha$-methylhistamine caused a steep increase for minutes $4-6$. The peak was at minute 5 at $1.271 \mathrm{AU}$ $(\mathrm{SD}=0.296)$. From then on, blood pressure gradually declined to $0.556 \mathrm{AU}(\mathrm{SD}=0.222)$. The arterial pressure was statistically different from the control group at minutes 5 and $8-18$.

Treatment with betahistine in combination with thioperamide reversed the betahistine-typical changes and caused blood pressure to remain close to basal values. Significant differences from the control group were monitored at minutes $8-11$.
The group receiving proxyfan together with betahistine showed similar effects to the aforementioned, meaning little deviation from baseline. Moreover, there was an overall tendency for blood pressure to decrease; in comparison with the control group, values at minutes 9 and 10 were significantly different.

Treatment with only ciproxifan led to no significant changes in blood pressure compared with the control group (fig. 3).

\section{The Effect of Adrenergic $\alpha_{2}$-Receptors on Arterial Blood Pressure}

Infusion of betahistine in combination with idazoxan caused an initial, slight drop in blood pressure, while overall there was little change from basal values. In comparison with the group receiving betahistine with saline 

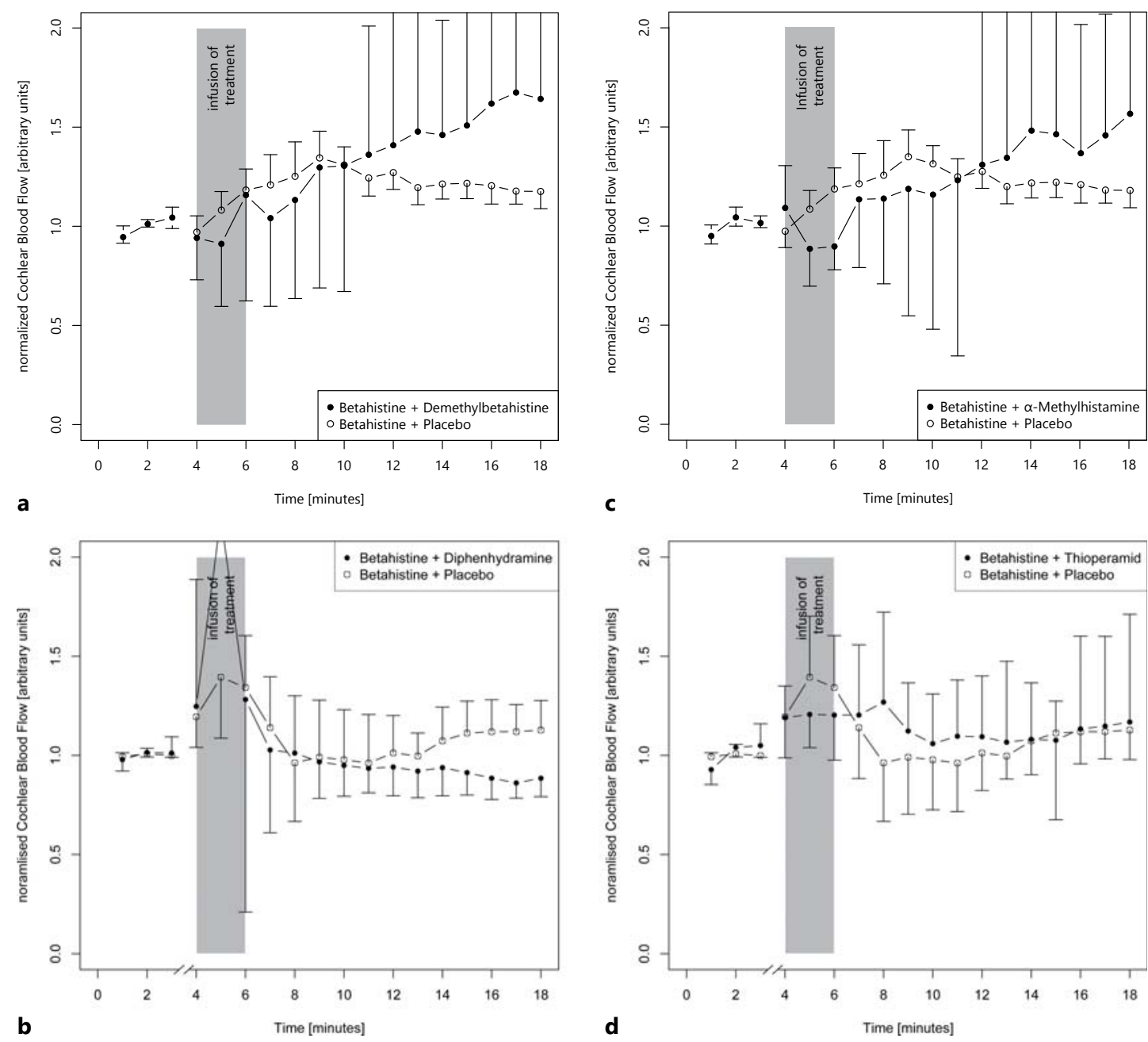

Fig. 2. Normalized cochlear blood flow over time before and after infusion of betahistine together with treatment. a Betahistine plus demethylbetahistine. b Betahistine plus diphenhydramine. c Betahistine plus $\alpha$-methylhistamine. $\mathbf{d}$ Betahistine plus thioperamide.

e Betahistine plus proxyfan. $\mathbf{f}$ Ciproxifan. $\mathbf{g}$ Betahistine plus idazoxan. $\mathbf{h}$ Betahistine plus yohimbine. Data are presented as means \pm SD. ${ }^{*} \mathrm{p}<0.05$.

(For figure $2 e-h$ see next page.)

solution, values for minutes $8-11$ were significantly different.

Treatment with yohimbine caused a similar effect, with an initial slight drop and the overall tendency for blood pressure to stay close to basal values. Comparison with the control group showed minutes 8,9 and 10 to be significantly different (fig. 3). See supplementary table 1 for the effects of all histaminergic receptors. For an overview of the mechanism of action, structure, receptor affinities, and dosages of receptor agonists and antagonists used, see online supplementary table 1 (for all online suppl. material, see www.karger.com/doi/10.1159/000368293).

\section{Discussion}

Betahistine is known to act as a weak agonist on the $\mathrm{H}_{1}$-receptor [Gbahou et al., 2010]. Assuming that the increase in cochlear blood flow is mediated through the $\mathrm{H}_{1}$-receptor, one would expect betahistine in combination with an $\mathrm{H}_{1}$-selective agonist like demethylbetahistine [Arai and Chiba, 1999] to cause an increase in cochlear blood flow at least comparable in extent with that of betahistine alone. In turn, one would expect treatment with an $\mathrm{H}_{1}$-receptor antagonist like diphenhydramine to reverse the increase in cochlear blood flow. 

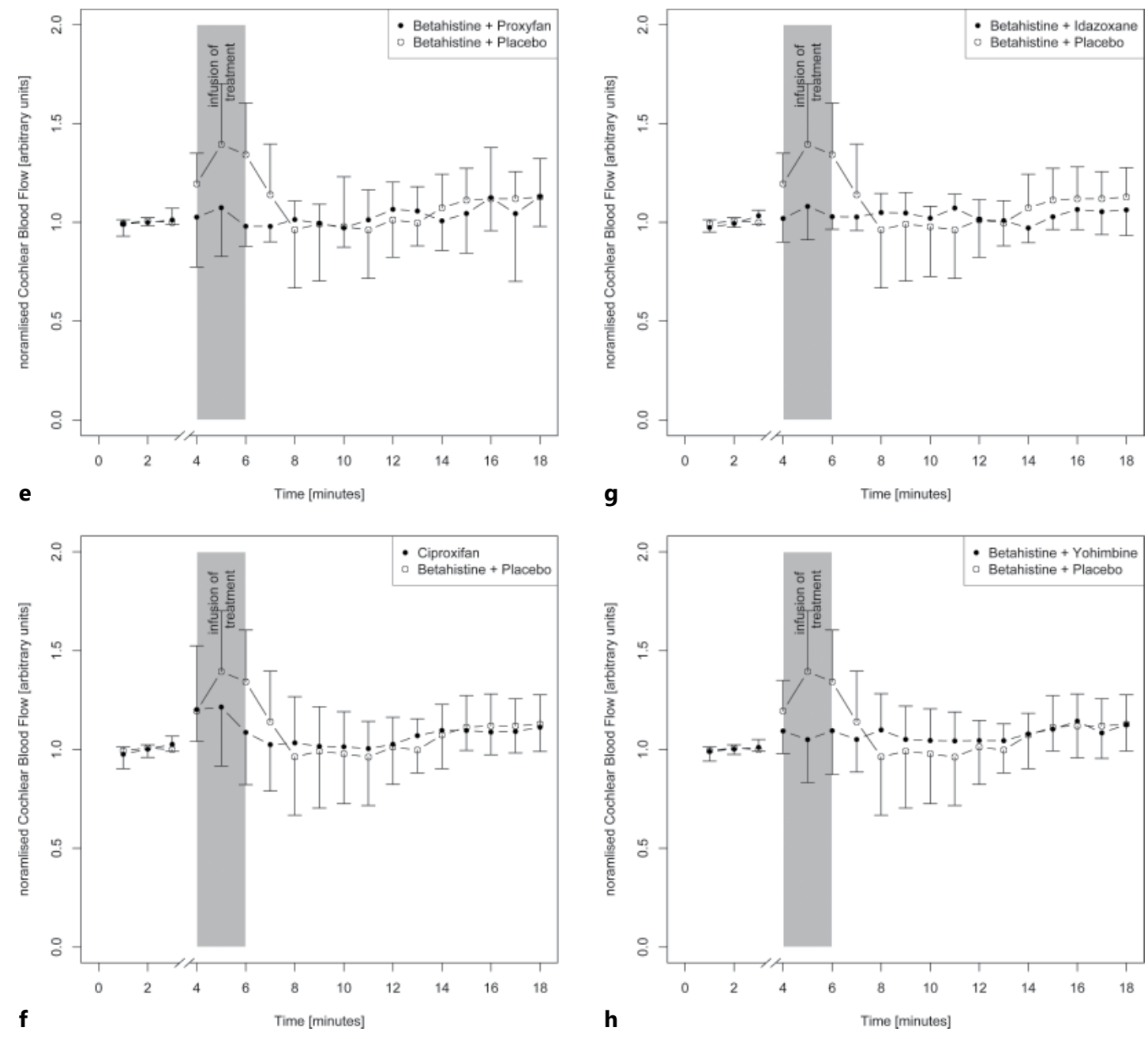

However, infusion of betahistine and demethylbetahistine caused a drop in mean arterial pressure and cochlear blood flow. It has previously been described before both betahistine and demethylbetahistine are capable of reducing blood pressure considerably [Tobia et al., 1974]. Overall, the data presented here concerning demethylbetahistine could be a result of the progressive failure of cochlear blood flow autoregulation due to the continuously decreasing mean arterial pressure [Brown and Nuttall, 1994]. During minutes 4-11 cochlear blood flow is most likely to be in a steady state - maintained by autoregulation - whilst from minute 11 onwards, cochlear blood flow decreases owing to the failure of autoregulation due to the systemic decline of blood pressure. This view is further supported by the increasing values of normalized cochlear blood flow seen from minute 9 onwards. With these assumptions in mind, it seems improbable that the $\mathrm{H}_{1}$-agonism of betahistine plays a major role in the mediation of betahistine effects. Fittingly, the group treated with the $\mathrm{H}_{1}$-antagonist diphenhydramine yielded no significant differences from the control group in terms of cochlear blood flow or arterial pressure in the present study. These findings are in line with the literature that suggests that the $\mathrm{H}_{1}$-receptor has no effect on betahistine-induced effects on cochlear blood flow [Laurikainen et al., 1993]. However, one more observation should be pointed out here: in previous experiments it has been shown that higher doses of betahistine show a significant yet short-lived drop in mean arterial pressure and cochlear blood flow at the beginning of betahistine infusion [Ihler et al., 2012a]. This initial and brief drop seems to be steeper the high- 

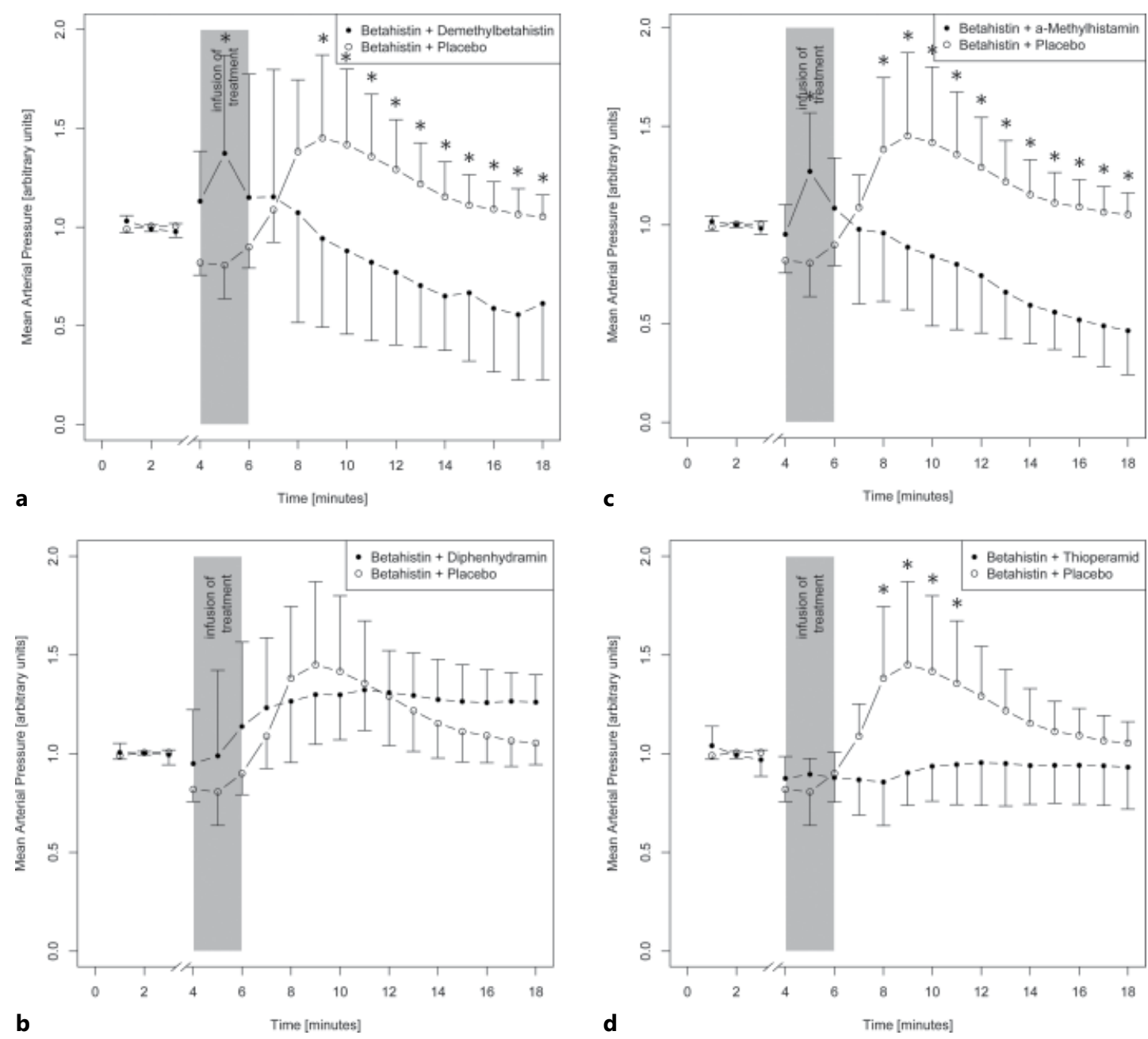

Fig. 3. Mean arterial pressure over time before and after infusion of betahistine together with treatment. a Betahistine plus demethylbetahistine. b Betahistine plus diphenhydramine. c Betahistine plus $\alpha$-methylhistamine. $\mathbf{d}$ Betahistine plus thioperamide. e Beta-

histine plus proxyfan. f Ciproxifan. g Betahistine plus idazoxan. $\mathbf{h}$ Betahistine plus yohimbine. Data are presented as means \pm SD. $* \mathrm{p}<0.05$.

(For figure $3 e-h$ see next page.)

er the concentration of betahistine [Dziadziola et al., 1999]. A similar although smaller drop (owing to our relatively low dosage of betahistine) was observed in the data presented here. The results of the diphenhydramine group suggest that this initial drop could potentially be reversed by the application of an $\mathrm{H}_{1}$-antagonist such as diphenhydramine. Bearing in mind the previous assumption that the $\mathrm{H}_{1}$-agonism of betahistine is most likely not involved in the increase of cochlear blood flow, it seems very possible that it is involved in the mediation of this initial drop in mean arterial pressure. These findings are in line with recent receptor affinity

studies that pointed out that betahistine is very potent at the $\mathrm{H}_{3}$-receptor and somewhat weaker at the $\mathrm{H}_{1}$-receptor [Fossati et al., 2001; Gbahou et al., 2010], raising the idea that side effects of betahistine, like the aforementioned drop in mean arterial pressure and cochlear blood flow, could be $\mathrm{H}_{1}$-mediated. This view is supported by the fact that typical betahistine side effects are also typically $\mathrm{H}_{1}$-receptor-related reactions, including flushing, headaches, skin reactions, and low blood pressure [Parsons, 1991; Jeck-Thole and Wagner, 2006].

Betahistine acts as a potent inverse agonist at the $\mathrm{H}_{3}$ receptor [Gbahou et al., 2010]. An inverse agonist is a li- 

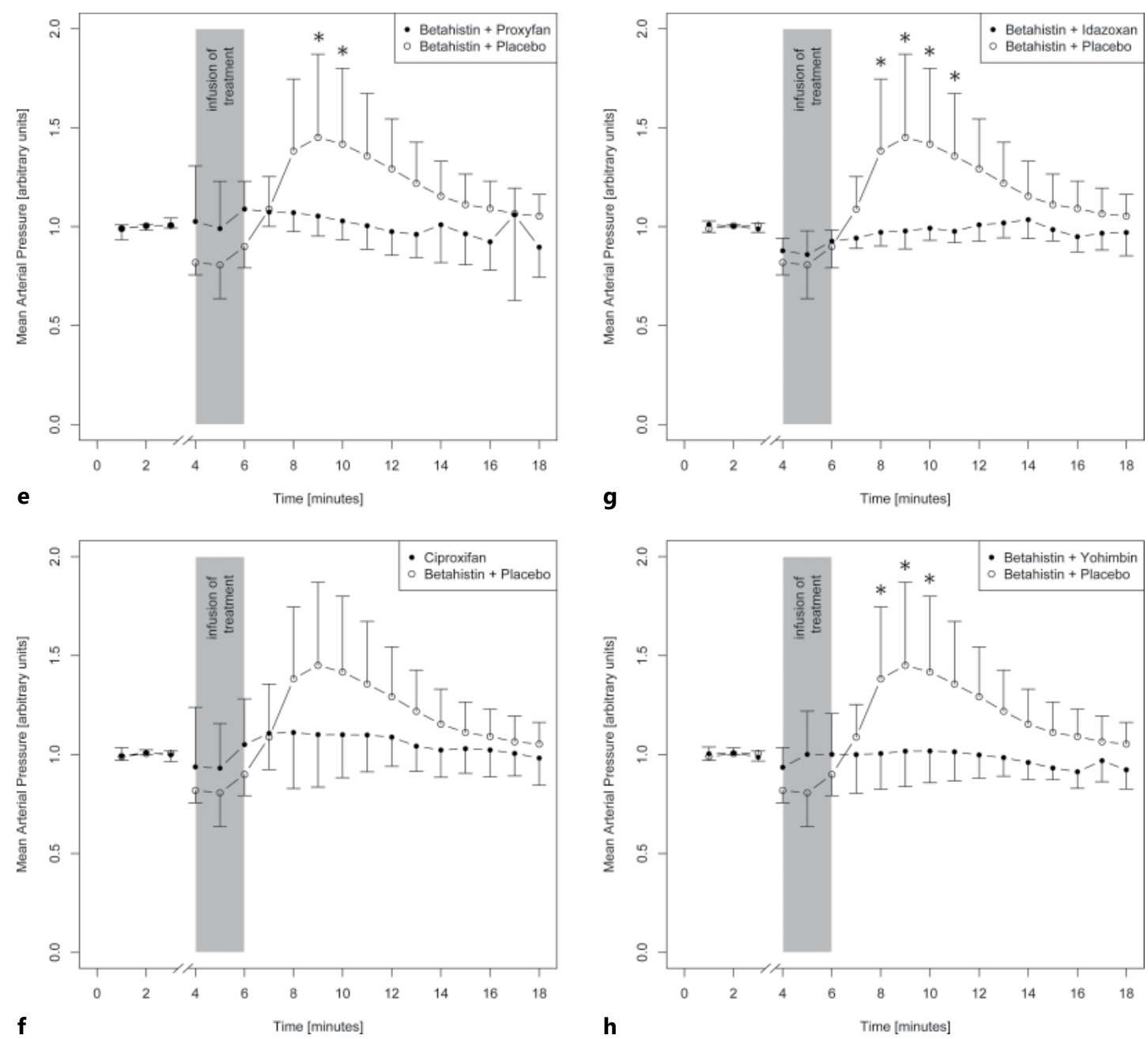

gand that binds to a receptor and decreases its constitutive activity [Kenakin and Williams, 2014]. Blocking of the $\mathrm{H}_{3}$-receptor with proxyfan or thioperamide caused the suppression of changes in cochlear blood flow typically mediated by betahistine. The suppression of betahistine-induced changes in cochlear blood flow by the blockage of the $\mathrm{H}_{3}$-receptor has previously been reported [Dziadziola et al., 1999] and was also observed in the present study. This indicates an involvement of the $\mathrm{H}_{3}$-receptor in betahistine-induced changes in cochlear blood flow. The fact that infusion of betahistine together with the $\mathrm{H}_{3}$ receptor agonist $\alpha$-methylhistamine, which acts as an opponent on this receptor in comparison with betahistine, caused a significant and lasting drop in both cochlear blood flow and mean arterial pressure further supports this theory. The fact that $\alpha$-methylhistamine in combina-

Effect of Betahistine on Cochlear Blood Flow through $\mathrm{H}_{3}$-Heteroreceptors tion with betahistine decreases cochlear blood flow and arterial blood pressure has not been reported so far and contradicts a study that conducted a similar experiment [Laurikainen et al., 1998]. In this study it had been proposed that $\alpha$-methylhistamine had no effect whatsoever on cochlear blood flow or blood pressure. However, in the aforementioned study, $\alpha$-methylhistamine dosaging had been more than 10-fold lower, whilst betahistine concentrations were 15 times higher than in this setting, resulting in an agonist-to-betahistine ratio of over 150 times lower than in the experiments reported here. Hence, the overall results indicated a probable involvement of the histamine $\mathrm{H}_{3}$-receptor in betahistine effects on cochlear blood flow. In order to elucidate this theory, one group was treated solely with ciproxifan, a competitive $\mathrm{H}_{3}$-inverse agonist [Motawaj and Arrang, 2011]. Infusion of 
ciproxifan caused a moderate increase in both cochlear blood flow and mean arterial pressure - however, not to an extent comparable with that of betahistine. A possible reason for this finding could be a relatively low affinity to adrenergic $\alpha_{2}$-receptors, which also seem to be involved in the mediation of betahistine-induced effects on cochlear blood flow and mean arterial pressure. Finally, even though ciproxifan has a lower $\mathrm{K}_{\mathrm{i}}$ value than betahistine at the histaminergic $\mathrm{H}_{3}$-receptor, and thus a greater affinity, this does not imply a stronger effect on the intracellular signaling cascades controlled by $\mathrm{H}_{3}$-receptors.

Taking into account all of the above considerations, it seems likely that the histamine $\mathrm{H}_{3}$-receptor plays a major role in the observed betahistine effects on cochlear blood flow.

It has been suggested several times that betahistine effects are not only mediated by histamine receptors, but that another class of receptors is involved as well. Candidates for this second receptor class have included acetylcholine [Laurikainen et al., 1993], imidazole [Laurikainen et al., 1998] and adrenergic [Laurikainen et al., 1998] receptors. It has been reported that pretreatment of animals with idazoxan, a potent adrenergic $\alpha_{2}$-receptor antagonist, is capable of entirely reversing the betahistine-induced changes in cochlear blood flow [Laurikainen et al., 1998]. To the best of our knowledge, there have been no in vivo or in vitro investigations on the extent to which betahistine exerts an effect on $\alpha_{2}$-receptors. In the presented data, betahistine effects were reversed by simultaneous infusion of both idazoxan, an $\alpha_{2}-/ \mathrm{I}_{2}$-receptor antagonist, and yohimbine, an $\alpha_{2}-/ 5-\mathrm{HT}_{3}$-antagonist, together with betahistine. Overall, the fact that blockage of the $\alpha_{2}$-receptor can also reverse betahistine changes similar to proxyfan and thioperamide suggests a noteworthy involvement of adrenergic $\alpha_{2}$-receptors in betahistine effects too. This view is further supported by the fact that betahistine was originally discovered as a drug while searching for adrenergic properties of pyridylalkylamines [Hunt and Fosbinder, 1942].

The fact that both the $\alpha_{2^{-}}$and the $\mathrm{H}_{3}$-receptor obviously play a major role in the mediation of betahistine effects raises a new question: do both receptors contribute directly to the increase in cochlear blood flow or could it be that they function as heteroreceptors that influence each other. Overall, the latter theory seems somewhat more likely, bearing in mind the fact that $\mathrm{H}_{3}$-receptors are known to have a significant impact on systemic and local noradrenaline release [Malinowska et al., 1998; Mazenot et al., 1999]. Moreover, it has been shown that $\mathrm{H}_{3}$-receptors are capable of interacting both with histaminergic and autonomic receptors in the periphery [Ishikawa and Sperelakis, 1987].

Taking this assumption even further, it could be postulated that the effects of betahistine at the cochlea are mere downstream effects caused by the increased blood pressure. Such a view could be supported by the fact that the cochlea lacks short-term autoregulation when systemic blood pressure increases [Vass et al., 1993], and that even successful betahistine therapy has failed to show a considerable impact on the endolymphatic hydrops on Ménière's patients [Gurkov et al., 2013]. Fittingly, none of the groups presented in this study happened to show a significant impact on normalized cochlear blood flow. However, it has also been shown that betahistine has a direct effect on vessels [Laurikainen et al., 1998; Santos-Silva et al., 2009]. In addition to that, a study conducted by this workgroup managed to show a significant increase of cochlear blood flow caused by the infusion of aminoethylpyridine, a product of betahistine metabolism [Bertlich et al., 2014]. At the same time, aminoethylpyridine had the tendency to lower mean arterial pressure, suggesting that betahistine effects are at least partially specific to the cochlear capillary network.

\section{Conclusion}

Betahistine effects seem to be mediated through histamine $\mathrm{H}_{3}$-receptors. Furthermore, the data presented here indicate an involvement of the adrenergic $\alpha_{2}$-receptors. The exact role of the adrenergic $\alpha_{2}$-receptors could be explained with the heteroreceptor properties of the $\mathrm{H}_{3^{-}}$ receptor.

\section{Acknowledgments}

This project was supported by funds from the Deutsche Forschungsgemeinschaft to Prof. Martin Canis under the grant code CA 629/2-1. The authors bear full responsibility for the content of this publication.

\section{Disclosure Statement}

The authors M. Bertlich, F. Ihler, S. Freytag, B.G. Weiss, and M. Canis declare that they have no conflicts of interest. Prof. M. Strupp declares to have received funds in return for consulting services to Abott, Pierre-Fabre and Biogen Idec as well as having received funds for the preparation of scientific training for Abbott, Biogen Idec, CSC, Henning Pharma, and GSK. 


\section{References}

Arai M, Chiba S: Endothelium-dependent vasodilatation mechanisms by histamine in simian but not in canine femoral arterial branches. J Auton Pharmacol 1999;19:267-273.

Baker M, Wayland $\mathrm{H}$ : On-line volume flow rate and velocity profile measurement for blood in microvessels. Microvasc Res 1974;7:131143.

Baldwin DL, Ohlsen KA, Miller JM, Nuttall AL: Cochlear blood flow and microvascular resistance changes in response to hypertonic glycerol, urea, and mannitol infusions. Ann Otol Rhinol Laryngol 1992;101:168-175.

Berlin M, Boyce CW, Ruiz Mde L: Histamine $\mathrm{H}_{3}$ receptor as a drug discovery target. J Med Chem 2011;54:26-53.

Bertlich M, Ihler F, Sharaf K, Weiss BG, Strupp M, Canis M: Betahistine metabolites, aminoethylpyridine, and hydroxyethylpyridine increase cochlear blood flow in guinea pigs in vivo. Int J Audiol 2014:53:753-759.

Brown JN, Nuttall AL: Autoregulation of cochlear blood flow in guinea pigs. Am J Physiol 1994; 266:H458-H467.

Canis M, Arpornchayanon W, Messmer C, Suckfuell M, Olzowy B, Strieth S: An animal model for the analysis of cochlear blood flow disturbance and hearing threshold in vivo. Eur Arch Otorhinolaryngol 2010;267:197-203.

Claes J, Van de Heyning PH: Medical treatment of Ménière's disease: a review of literature. Acta Otolaryngol Suppl 1997;526:37-42.

Claes J, Van de Heyning PH: A review of medical treatment for Ménière's disease. Acta Otolaryngol Suppl 2000;544:34-39.

Curwain BP, Holton P, Spencer J: The effect of betahistine on gastric acid secretion and mucosal blood flow in conscious dogs. Br J Pharmacol 1972;46:351-354.

Dziadziola JK, Laurikainen EL, Rachel JD, Quirk WS: Betahistine increases vestibular blood flow. Otolaryngol Head Neck Surg 1999;120: 400-405.

Fossati A, Barone D, Benvenuti C: Binding affinity profile of betahistine and its metabolites for central histamine receptors of rodents. Pharmacol Res 2001;43:389-392.

Gbahou F, Davenas E, Morisset S, Arrang JM: Effects of betahistine at histamine $\mathrm{H}_{3}$ receptors: mixed inverse agonism/agonism in vitro and partial inverse agonism in vivo. J Pharmacol Exp Ther 2010;334:945-954.
Gurkov R, Flatz W, Keeser D, Strupp M, ErtlWagner B, Krause E: Effect of standard-dose betahistine on endolymphatic hydrops: an MRI pilot study. Eur Arch Otorhinolaryngol 2013;270:1231-1235.

Hunt WH, Fosbinder RJ: A study of some $\beta-2$, and 4 , pyridylalkylamines. J Pharmacol Exp Ther 1942;75:299-307.

Ihler F, Bertlich M, Sharaf K, Strieth S, Strupp M, Canis M: Betahistine exerts a dose-dependent effect on cochlear stria vascularis blood flow in guinea pigs in vivo. PLoS One 2012a;7:e39086.

Ihler F, Strieth S, Pieri N, Gohring P, Canis M: Acute hyperfibrinogenemia impairs cochlear blood flow and hearing function in guinea pigs in vivo. Int J Audiol 2012b;51:210-215.

Ishikawa S, Sperelakis N: A novel class $\left(\mathrm{H}_{3}\right)$ of histamine receptors on perivascular nerve terminals. Nature 1987;327:158-160.

James A, Burton MJ: Betahistine for Ménière's disease or syndrome. Cochrane Database Syst Rev 2001;1:CD001873.

James A, Thorp M: Ménière's disease. Clin Evid 2005; 14:659-665.

Jeck-Thole S, Wagner W: Betahistine: A retrospective synopsis of safety data. Drug Saf 2006;29:1049-1059.

Kenakin T, Williams M: Defining and characterizing drug/compound function. Biochem Pharmacol 2014;87:40-63.

Klyscz T, Junger M, Jung F, Zeintl H: Cap image a new kind of computer-assisted video image analysis system for dynamic capillary microscopy (in German). Biomed Tech (Berl) 1997; 42:168-175.

Laurikainen E, Miller JM, Nuttall AL, Quirk WS The vascular mechanism of action of betahistine in the inner ear of the guinea pig. Eur Arch Otorhinolaryngol 1998;255:119-123.

Laurikainen E, Miller JF, Pyykko I: Betahistine effects on cochlear blood flow: from the laboratory to the clinic. Acta Otolaryngol Suppl 2000;544:5-7.

Laurikainen E, Miller JM, Quirk WS, Kallinen J, Ren T, Nuttall AL, Grenman R, Virolainen E: Betahistine-induced vascular effects in the rat cochlea. Am J Otol 1993;14:24-30.

Malinowska B, Godlewski G, Schlicker E: Histamine $\mathrm{H}_{3}$ receptors - general characterization and their function in the cardiovascular system. J Physiol Pharmacol 1998;49:191-211.

Mazenot C, Ribuot C, Durand A, Joulin Y, Demenge $\mathrm{P}$, Godin-Ribuot $\mathrm{D}$ : In vivo demonstration of $\mathrm{H}_{3}$-histaminergic inhibition of cardiac sympathetic stimulation by $r$ - $\alpha$-methylhistamine and its prodrug BP 2.94 in the dog. Br J Pharmacol 1999;126:264-268.
Ménière P: Congestions cerebrales apoplectiformes. Gaz Med Paris 1861a;16:55.

Ménière P: Pathologie auriculaire: mémoire sur des lésions de l'oreille interne donnant lieu à des symptômes de congestion cérébrale apoplectiforme. Gaz Med Paris 1861b;16:597-601.

Motawaj M, Arrang JM: Ciproxifan, a histamine $\mathrm{H}_{3}$-receptor antagonist/inverse agonist, modulates methamphetamine-induced sensitization in mice. Eur J Neurosci 2011;33:1197-1204.

Nuttall AL: Velocity of red blood cell flow in capillaries of the guinea pig cochlea. Hear Res 1987; 27:121-128.

Ohlsen KA, Didier A, Baldwin D, Miller JM, Nuttall AL, Hultcrantz E: Cochlear blood flow in response to dilating agents. Hear Res 1992;58: 19-25.

Parsons ME: Histamine receptors: an overview. Scand J Gastroenterol Suppl 1991;180:46-52.

Redon C, Lopez C, Bernard-Demanze L, Dumitrescu M, Magnan J, Lacour M, Borel L: Betahistine treatment improves the recovery of static symptoms in patients with unilateral vestibular loss. J Clin Pharmacol 2011;51:538-548.

Santos-Silva AJ, Cairrao E, Marques B, Verde I: Regulation of human umbilical artery contractility by different serotonin and histamine receptors. Reprod Sci 2009;16:1175-1185.

Strupp M, Thurtell MJ, Shaikh AG, Brandt T, Zee DS, Leigh RJ: Pharmacotherapy of vestibular and ocular motor disorders, including nystagmus. J Neurol 2011;258:1207-1222.

Thorp MA, James AL: Prosper Ménière. Lancet 2005;366:2137-2139.

Tobia AJ, Sternson LA, Walsh GM, LaRocca JP: The role of demethylbetahistine in the depressor response to betahistine in the rat. Proc Soc Exp Biol Med 1974; 145:778-781.

Vass Z, Bari F, Barzo P, Czigner J, Bodosi M: Lack of short-term autoregulation in the cochlear microcirculation in guinea pigs. Eur Arch Otorhinolaryngol 1993;250:101-104.

Woldbaek PR, Stromme TA, Sande JB, Christensen G, Tonnessen T, Ilebekk A: Evaluation of a new fiber-optic pressure recording system for cardiovascular measurements in mice. Am J Physiol Heart Circ Physiol 2003; 285:H2233-H2239.

Zeintl H, Sack FU, Intaglietta M, Messmer K: Computer-assisted leukocyte adhesion measurement in intravital microscopy. Int J Microcirc Clin Exp 1989;8:293-302.
Effect of Betahistine on Cochlear Blood Flow through $\mathrm{H}_{3}$-Heteroreceptors
Audiol Neurotol 2015;20:283-293 